\title{
Immediate and Short-term Outcome of Acute Disseminated Encephalomyelitis (ADEM) after corticosteroid therapy
}

\author{
M Mahbub ${ }^{1}$, S Sarker ${ }^{2}$, S C Mazumder ${ }^{3}$
}

1 Prof. Mustafa Mahbub

MBBS, DCH, FCPS

Professor and Head

Dept. of Paediatric Neurosciences

Bangladesh Institute of Child

Health (BICH)

Dhaka Shishu (Children's) Hospital

${ }^{2}$ Dr. Shaoli Sarker

MBBS, FCPS

Assistant Professor

Dept. of Paediatric Neurosciences

Bangladesh Institute of Child

Health (BICH)

Dhaka Shishu (Children's) Hospital

${ }^{3}$ Dr. Suraj C Mozumder

MBBS, DCH

Registrar

Dept. of Paediatric Neurosciences

Dhaka Shishu (Children's) Hospital

Correspondence

Dr. Mustafa Mahbub

MBBS, DCH, FCPS

Professor and Head

Dept. Paediatric Neurosciences

Dhaka Shishu (Children's ) Hospital

Bangladesh Institute of Child Health (BICH)

Email : mm231956@gmail.com

\begin{abstract}
Background : Acute disseminated encephalomyelitis (ADEM) is an acute demyelinating disorder of the central nervous system (CNS) occurring predominantly but not exclusively in children. The presence of severe disturbance of consciousness together with multifocal neurological symptoms and signs especially in a child under 10 years of age; favours a diagnosis of ADEM. Neuroimaging is essential investigation for establishing the diagnosis of ADEM. High-dose steroid treatment frequently results in a dramatic clinical improvement.
\end{abstract}

Objective: This study aimed to describe our experience with Acute Disseminated Encephalomyelitis (ADEM) focusing on the clinical features, neuroimaging, and outcome after treatment with high-dose steroid.

Method: This retrospective observational study was conducted in children who were admitted as inpatients in Paediatric Neurosciences Department of Dhaka Shishu Hospital (DSH) with the diagnosis of ADEM during the period of 2017- 2019. All patients got high dose IV methylprednisolone for 5 days followed by 2 weeks tapering dose of steroid. Outcome was observed on the 7th day of treatment and 6 months after discharge from hospital.

Result: A total of 16 patients who were diagnosed as ADEM were included in this study. Twelve children (75\%) had a recent upper respiratory tract illness. Patients presented most often with motor deficits $(88 \%)$ and secondly with altered consciousness $(63 \%)$ followed by seizure ( $50 \%)$. MRI brain was the preferable neuroimaging which mostly $(41.7 \%)$ showed multifocal symmetrical demyelination patch. On the 7th day of steroid treatment, significant improvement in motor function and level of consciousness occurred ( $p$ values were $0.001 \%$ and $0.014 \%$ respectively). After 6 months of discharge from hospital; no motor deficit, age-appropriate cognitive level and no seizure in $71 \%, 57 \%$ and $71 \%$ respectively.

Conclusion: High dose corticosteroid treatment in ADEM is significantly effective in improvement of motor impairment and consciousness level on immediate follow up.

DOI: https://doi.org/10.3329/nimcj.v11i2.54064

Northern International Medical College Journal Vol. 11 No. 2 January 2020, Page 468-470

\section{Introduction}

Acute disseminated encephalomyelitis (ADEM) is an immune mediated disease of the brain. It occurs following a viral infection but may appear following vaccination, bacterial or parasitic infection. ${ }^{1}$ It occurs in all ages, with an average age of around 5 to 8 years old. Full recovery is seen in 50 to $75 \%$ of cases. The estimated mortality rate may be as high as $5 \% .^{2}$ the inflammatory lesions are found in the subcortical and central white matter and cortical gray-white junction of cerebral hemispheres, cerebellum, brainstem, and spinal cord. ${ }^{3}$

Acute Disseminated Encephalomyelitis (ADEM) is a brief but intense attack of inflammation (swelling) in the brain and spinal cord and occasionally the optic nerves that damages the brain's myelin.

ADEM occurs in all parts of the world and in all ethnic groups. According to population-based studies, the incidence of ADEM to be 0.3-0.6 per 100,000 per year ${ }^{4,5}$ The median age at presentation of ADEM is $5-8$ years, with male predominance. ${ }^{6,7}$

Symptoms may appear following a viral or bacterial infection (Measles, Mumps, Chicken pox, Rubella, Whooping cough) and rarely following vaccination. Most cases of ADEM occur about 2 to 30 days after an infection or up to three months following a vaccination. Five to ten 
percent of ADEM cases could be associated with vaccination..$^{8,9}$ The risk of post immunization ADEM is significantly lower than the risk of developing ADEM following the infection itself. ${ }^{10}$

The symptoms of ADEM come on quickly, encephalitis-like symptoms. Severe disturbance of conscious together with multifocal neurological sign and symptoms -in child under-10 years age-suspects ADEM. Fever, headache (can be prolonged and severe in children) nausea and vomiting are the cardinal features. Neurological changes including Confusion, drowsiness or coma, weakness in the arms or legs unsteady walk (ataxia) Numbness or tingling (sensory changes) Trouble with vision, often in both eyes (optic neuritis) Seizures, Trouble in swallowing. ${ }^{11}$

This study was conducted to see clinical features, neuroimaging, and outcome after treatment with high-dose steroid in a cohort of children with acute disseminated encephalomyelitis (ADEM)

\section{Methods}

This is an retrospective observational hospital based study, carried out in the Paediatric Neurosciences Department of Dhaka Shishu Hospital ( DSH ), Bangladesh, over a period of 2 years from March 2017 through February 2019. All children who fulfilled the clinical and neuroimaging criteria for ADEM diagnosis were included. Sociodemographic profile were observed. All patients got high dose IV methylprednisolone (MP) $30 \mathrm{mg}$ $/ \mathrm{kg} /$ day for 5 days followed by 2 weeks tapering dose of oral prednisolone.

Outcome was observed on the $7^{\text {th }}$ day of treatment in parameters of consciousness level, seizure, and motor function. After 6 months of discharge from hospital; motor function, cognitive state and seizure outcome were measured.

Ethical permission was taken from Ethical Review Committee of Dhaka Shishu Hospital and Bangladesh Institute of Child Health. Number, percentages were described in frequency and distribution. Association of outcome with different variables was obtained by chi -squared. Data was analyzed in SPSS version 21.

\section{Results}

Among 16 children who had ADEM, male was found 11 (69\%) and female were $5(31 \%)$. Male female ratio was 2.2: 1 . (Fig -1 )

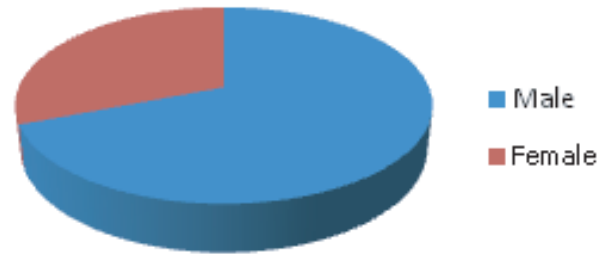

Figure 1: Sex Distribution (no-16)
Maximum children belong to age group $1-5$ years and $5-10$ years, respectively. Most of the patients were from rural area. (Table I)

Table - I : Demographic profile

$\begin{array}{ccc}\text { Age in year } & \text { Number } & \text { Percentage } \\ 1-5 & 7 & 44 \% \\ 5-10 & 6 & 37 \% \\ >10 & 3 & 19 \% \\ \text { Residence } & & \\ \text { Urban } & 5 & 31.25 \% \\ \text { Rural } & 11 & 68.75 \%\end{array}$

Twelve cases $(75 \%)$ had history of recent upper respiratory tract infection. $9(60 \%)$ had motor deficit (focal or generalized), 10 $(63 \%)$ had altered consciousness, $8(50 \%)$ presented with seizure.

Table - II : Clinical features of the patients on admission.

$\begin{array}{ccc}\text { C/F on admission } & \text { Number } & \text { Percentage } \\ \text { Motor deficits } & 14 & 88 \% \\ \text { Altered consciousness } & 10 & 63 \% \\ \text { Seizure } & 8 & 50 \%\end{array}$

Table - III : Investigation findings

\begin{tabular}{ccc}
\hline Investigations $(\mathbf{n = 1 6})$ & Number of patients & Percentage \\
MRI brain & 12 & \\
Multifocal symmetrical demyelination patch & 5 & $41.7 \%$ \\
Asymmetrical demyelination patch & 2 & $16.6 \%$ \\
Involvement of basal ganglia and thalami & 4 & $33.3 \%$ \\
Involvement of brain stem & 3 & $25 \%$ \\
CT brain & 4 & \\
Indistinct region of low density within the white matter & 3 & $75 \%$ \\
Cortical atrophy & 1 & $25 \%$ \\
CSF Study & 8 & \\
Elevated protein & 6 & $75 \%$ \\
Normal CSF Study & 2 & $25 \%$
\end{tabular}

After high dose IV methylprednisolone for 5 days followed by tapering dose of oral prednisolone, the immediate outcome was followed on the $7^{\text {th }}$ day after treatment was started. (Table IV)

Table - IV : Immediate outcome after treatment with steroid

$\begin{array}{lccc}\text { Clinical feature } & \text { On admission } & \begin{array}{c}\text { On the } 7^{\text {th }} \text { day of } \\ \text { Steroid treatment }\end{array} & \boldsymbol{p} \text { value } \\ \text { Level of consciousness }(n=16) & 2 & 6 & 0.22 \\ \text { GCS - 15 } & 7 & 9 & 0.47 \\ \text { GCS 10-15 } & 7 & 1 & 0.014 \\ \text { GCS 8-10 } & 8 & 3 & 0.06 \\ \text { Seizure } & 14 & 4 & 0.001 \\ \text { Motor function impaired } & 14 & & \end{array}$

After 6 months of discharge, the outcome was measured when 
the patients came back for follow up at Child Development Center of Dhaka Shishu Hospital. 2 patients (12.5\%) were lost for follow up. The outcome was observed in 14 patients (87.5\%). (Table - V)

$\begin{array}{lcc}\text { Table V : Clinical feature after } \mathbf{6} \text { months }(\mathbf{n = 1 4}) & \text { Percentage } \\ \text { Clinical feature } & \text { Number } & \\ \text { Motor } & 10 & 71 \% \\ \text { No deficit } & 3 & 22 \% \\ \text { Hemiparesis } & 1 & 7 \% \\ \text { Quadriparesis } & & \\ \text { Cognitive state } & 8 & 57 \% \\ \text { Age appropriate } & 6 & 43 \% \\ \text { Delayed } & & \\ \text { Seizure } & 10 & 71 \% \\ \text { No } & 4 & 29 \% \\ \text { Yes } & & \end{array}$

\section{Discussion}

In this study, 16 cases of ADEM were identified over a 2-years period. In the past ADEM has been associated with vaccinations or viral exanthema. No clear-cut preceding infectious cause was identified in majority of instances. In our study, 12 cases (75\%) had history of recent upper respiratory tract infection. There was no history of preceding vaccination in any of the patients. Our youngest patient was 2 years old. The male/female distribution showed no particular trend and male predominance in others study as in ours. ${ }^{11}$

Symptoms and signs at presentation may differ probably due to differences in the ages of the patients. Disturbed consciousness, motor impairment and seizure are frequently found in many series including ours. ${ }^{12}$

Early studies of ADEM reported mortality rates up to $20 \%$ with a high incidence of neurological sequele in survivors. ${ }^{13-16}$ In our study mortality was nil. Paediatric reports have suggested a more favorable prognosis attributed to the treatment with corticosteroids. ${ }^{13-16}$

In our study neurological evaluation showed $88 \%$ of cases had motor deficit. Seizure in our study were found in $50 \%$ cases which is similar with other studies. ${ }^{16}$ In our study 8 cases were subjected to cerebrospinal fluid analysis (CSF) to exclude encephalitis and $75 \%$ had elevated CSF proteins.

Multiple foci of increased signal intensity in T2 and FLAIR images within the cerebral white matter were found in all patients who underwent MRI brain. The demyelination patches were symmetrical in distribution in $41.7 \%$ and asymmetrical in $16.6 \%$. Though not gold standard, CT scan of brain were performed when MRI brain was not affordable due to financial constraints. Indistinct region of low density within the white matter was found in $75 \%$ cases that underwent CT scan of brain. The findings of our study were consistent with other reports. ${ }^{17,18}$

In this study time of corticosteroids initiation ranged from first day to more than one week. Comparable results were obtained in other studies. ${ }^{18}$ Data from other reports showed IVIG was needed in $37.5 \%,{ }^{15}$ but fortunately our patients needed no further IVIG therapy without that they were clinically improved only with glucocorticoid therapy.

\section{Conclusion}

In conclusion, in this study we found that clinical pattern of Acute disseminating encephalomyelitis is variable. Motor deficit and altered consciousness was the commonest presentation. Seizure also reported in significant percentage. Immediate outcome with high dose methylprednisolone was better in altered consciousness and motor deficit also improved after six months. Early high dose MP followed by oral prednisolone treatment could be a good option of treatment in this case.

\section{Reference}

1. Dale RC. Acute disseminated encephalomyelitis. Semin Pediatr Infect Dis. 2003; 14(2):90-5. doi: 10.1053/spid.2003.127225. [PubMed] [CrossRef] [Google Scholar]

2. Banwell B, Kennedy J, Sadovnick D, Arnold DL, Magalhaes S, Wambera K, et al. Incidence of acquired demyelination of the CNS in Canadian children. Neurology. 2009;72(3):232-9. doi: 10.1212/01.wnl.0000339482.84392.bd. [PubMed] [CrossRef] [Google Scholar]

3. Stonehouse M, Gupte G, Wassmer E, Whitehouse WP. Acute disseminated encephalomyelitis: recognition in the hands of general paediatricians. Arch Dis Child. 2003;88(2):122-4. doi: 10.1136/adc.88.2.122. [PMC free article] [PubMed] [CrossRef] [Google Scholar]

4. Torisu $H$, Kira R, Ishizaki $Y$, et al. Clinical study of childhood acute disseminated encephalomyelitis, multiple sclerosis, and acute transverse myelitis in Fukuoka Prefecture, Japan. Brain Dev 2010;32:454-462. 17.

5. Xiong $\mathrm{CH}$, Yan $\mathrm{Y}$, Liao Z, et al. Epidemiological characteristics of acute disseminated encephalomyelitis in Nanchang, China: a retrospective study. BMC Public Health 2014;14:111

6. Pohl D, Hennemuth I, von Kries R, Hanefeld F. Paediatric multiple sclerosis and acute disseminated encephalomyelitis in Germany: results of a nationwide survey. Eur ] Pediatr 2007; 166:405-412

7. Tenembaum S, Chamoles N, Fejerman N. Acute disseminated encephalomyelitis: a longterm follow-up study of 84 pediatric patients. Neurology 2002;59: 1224-1231.

8. Huynh W, Cordato DJ, Kehdi E, Masters LT, Dedousis C. Post-vaccination encephalomyelitis: literature review and illustrative case. J Clin Neurosci 2008;15(18976924):1315-22.

9. Bennetto L, Scolding N. Inflammatory/post-infectious encephalomyelitis. J Neurol Neurosurg Psychiatry 2004;75(Suppl. 1(14978147)):22-8.

10. Karussis D, Petrou P. The spectrum of post-vaccination inflammatory CNS demyelinating syndromes. Autoimmun Rev 2014;13:215-224.

11.B Anlar ${ }^{1}$, C Basaran, G Kose, A Guven.Acute disseminated encephalomyelitis in children: outcome and prognosis. Neuropediatrics.2003 Aug;34(4):194-9.

12. Abdelrahim AS, Mostafa AM, Ashraf AT, Marwa IM.Pattern and outcome of acute disseminated encephalomyelitis (ADEM) in children: experience in a tertiary center, upper Egypt. Electronic Physician.July 2016, Volume: 8. Issue: 7, Pages: 2679-2685, DOI: http://dx.doi.org/10.19082/2679

13. Tenembaum S, Chamoles N, Fejerman N. Acute disseminated encephalomyelitis; a long term follow-up study of 84 pediatric patients. Neurology. 2002;59:1224-1231 ( B1)

14. Hynson JL, Kornberg AJ, Coleman LT, Shield L, Harvey AS, Kean MJ. Clinical and neuroradiologic features of acute disseminated encephalomyelitis in children. Neurology. 2001;56:1308-1312 ( B4 )

15. Murthy SN, Faden HS, Cohen ME, Bakshi R. Acute disseminated encephalomyelitis in children. Pediatrics. 2002;110(2). ( B 15 )

16. Hung KL, Liao HT, Tsai ML. Postinfectious encephalomyelitis : etiologic and diagnostic trends. J Child Neurol 2000;15:666-670 ( A- 8)

17. Weng WC, Peng SS, Lee WT, Fan PC, Chien YH, Du JC, et al. Acute disseminated encephalomyelitis in children: one medical center experience. Acta Paediatr Taiwan. 2006; 47(2): 67-71. PMID: 16927630.( D- 16)

18. Sundar U, Shrivastava MS. Acute disseminated encephalomyelitis--a prospective study of clinical profile and in-hospital outcome predictors. J Assoc Physicians India. 2012; 60: 21-6. PMID: 22799110. ( D- 25). 